\title{
Law and Society Studies in Context: Suggestions for a Cross-Country Comparison of Socio-Legal Research and Teaching
}

\author{
Tanja Herklotz
}

(Received 30 August 2020; accepted 15 September 2020)

\begin{abstract}
Cultures of legal and socio-legal scholarship, like legal cultures themselves, are shaped by their respective historical, cultural, economic, and socio-political context. Socio-legal—or law and society—studies are thus pursued and taught differently in different parts of the world. This Article suggests making sociolegal studies the object of comparative research, so as to understand and explain commonalities, differences, and context dependencies in socio-legal scholarship and teaching in different countries. Such comparative endeavors help to translate between different academic languages and to critically reflect upon one's own research methods and system of legal education. They prove useful for scholars planning research in other parts of the world or engaging in cross-country collaborative research projects, and for research institutions and policymakers involved in reforming research funding and legal education. But how do we go about comparing socio-legal studies? More specifically, why, what, and how do we compare, and what are the challenges that we may face when pursuing such comparative endeavors? This Article gives an overview of potential research questions that a comparison between socio-legal studies may address, the sources that comparativists may draw on, the methods such a comparative endeavor may use to collect and analyze data, and the challenges researchers may face when attempting to compare socio-legal studies in different parts of the world.
\end{abstract}

Keywords: Law and society studies; socio-legal scholarship and teaching; cross-country comparison; research methods; Germany and UK

\section{A. Introduction}

What are socio-legal studies? The answer to this question might differ when posed in different parts of the world. Socio-legal—or law and society—scholars in the US, Germany, or India might describe their way of working and the scope of their research in different terms. Scholarly articles, textbooks, and conferences on law and society in the UK, Japan, or Mexico might articulate different understandings of the purpose of socio-legal scholarship. This is because cultures of legal and socio-legal scholarship, like legal cultures themselves, are also shaped by their respective historical, cultural, economic, and socio-political context. How socio-legal studies emerged and developed over time, and how they are pursued and taught today thus differs, depending on where we are.

\footnotetext{
${ }^{\star}$ Researcher at the Chair for Public and Comparative Law at Humboldt-University Berlin. In writing this Article I benefitted greatly from my research stays at the Center for the Study of Law and Society at Berkeley Law and at the Centre for Law and Society at the University of Cardiff. I wish to thank Naomi Creutzfeldt, Jen Hendry, and Christian Boulanger for their feedback on an earlier draft of this Article.
}

(C) The Author(s), 2020. Published by Cambridge University Press on behalf of the German Law Journal. This is an Open Access article, distributed under the terms of the Creative Commons Attribution licence (http://creativecommons.org/licenses/by/4.0/), which permits unrestricted re-use, distribution, and reproduction in any medium, provided the original work is properly cited. 
Reflections about socio-legal studies in specific countries-such as Germany ${ }^{1}$ or the $\mathrm{UK}^{2}{ }^{2}$ as well as other parts of the world ${ }^{3}$ - are not uncommon. They are, however, rarely comparative ${ }^{4}$ in nature, and usually only focus on the development and operation of socio-legal studies in one particular country. It is, however, especially the comparative angle that provides for interesting insights about the context dependency of socio-legal research and teaching. Some aspects that are of interest here, such as legal education ${ }^{5}$ or legal academia, ${ }^{6}$ have been addressed by studies of comparative legal culture or comparative law (and society). There are, however, many more topics to explore when comparing socio-legal studies in different parts of the world. Scholarship engaging with sciences from a historical or sociological viewpoint-history of science, sociology of science, or science studies-addresses questions regarding the development of particular scientific fields and the impact of certain historical, political, cultural, or economic factors on that field. This scholarship, however, has largely focused on the natural sciences, rather than the social sciences, and does not usually address fields such as legal—or socio-legal—studies. ${ }^{7}$

In this Article, I suggest that looking at socio-legal studies from a comparative angle-in other words, making socio-legal studies the object of a comparative research project-is a very fruitful endeavor. I will explain how scholars, research institutions, and policymakers may benefit from such scholarly endeavors and how we can go about comparing the ways scholars pursue and teach socio-legal studies - or legal studies more broadly, for that matter. In Section B, I will first suggest some aims that a comparative project on socio-legal studies could pursue and some potential research questions it could address. I will then deal with potential research objects, first by speaking about questions of case selection - in Section C - and then by addressing sources and methods of data collection - in Section D. In Section E, I will further inquire about how to pursue the kind of comparative approach that I suggest in this Article by dealing with different methods of data analysis. Lastly, in Section F, I will address potential challenges that such comparative endeavors may face and provide a brief conclusion.

\footnotetext{
${ }^{1}$ See generally Stefan Machura, German Sociology of Law, 32 AM. Sociologist 41 (2001) [hereinafter Machura, German Sociology of Law]; Stefan Machura, Rechtssoziologie, in HANDbUCH SpeZIELle SozIologien (Georg Kneer \& Markus Schroer eds., 2010); Doris Lucke, Germany, in ENCYClopedia of LAW AND SOCIETY: AMERICAN AND Global Perspectives (David S. Clark ed., 2007); Stefan Machura, German Sociology of Law: A Case of Path Dependency, 8 INT'L J.L. ConTeXT 506 (2012).

${ }^{2}$ See generally C.M. Campbell \& Paul Wiles, The Study of Law in Society in Britain, 10 L. \& Soc'y Rev. 547 (1976); David S. Clark, United Kingdom, in ENCYClopedia of LAW AND SOCIETY: AMERICAN AND Global Perspectives, supra note 1 [hereinafter Clark, United Kingdom]; Dermot Feenan, Exploring the 'Socio' of Socio-Legal Studies, in ExPLORING 'SocIO' Socio-Legal Studies (Dermot Feenan ed., 2013); Hilary Sommerlad, Developments in Socio-Legal Studies: Subjects and Methodologies - the Anglo-Saxon Model, 36 ReCHT DER WerkelijKheID (2015).

${ }^{3}$ For the Netherlands, see Marc Hertogh, Mind the (New) Gap: A Selective Survey of Current Law and Society Research in the Netherlands, 8 INT'L J.L. ConTEXT 137 (2012); for Denmark, see Ole Hammerslev \& Mikael Rask Madsen, The Return of Sociology in Danish Socio-Legal Studies: A Survey of Recent Trends, 10 INT'L J.L. ConTEXT 397 (2014); for Portugal, see Pierre Guibentif, Law in the Semi-Periphery: Revisiting an Ambitious Theory in the Light of Recent Portuguese Socio-Legal Research, 10 InT'L J.L. ConteXt 538 (2014); for Belgium, see Stephan Parmentier, A Tale of Two Worlds: A (Very) Select Overview of Socio-Legal Studies in Belgium, 12 INT'L J.L. CONTEXT 81 (2016). For more information on this topic generally, see the different country reports in the ENCYClOPEDia of LAW AND SOCIETY: AMERICAN AND Global PERSPECTIVES, supra note 1 .

${ }^{4}$ But see Naomi Creutzfeldt, Traditions of Studying the Social and the Legal: A Short Introduction to the Institutional and Intellectual Development of Socio-Legal Studies, in Routledge HaNdbooK OF Socio-Legal Theory and Methods (Naomi Creutzfeldt, Marc Mason \& Kirsten McConnachie eds., 2019); Stefan Machura, Milestones and Directions: Socio-Legal Studies in Germany and the United Kingdom, in this issue [hereinafter Machura, Milestones and Directions].

${ }^{5}$ See Julian Webb, Education, Legal, in ENCYClOPEDIA OF LAW AND SOCIETY: AMERICAN AND GlOBAL PERSPECTIVES, supra note 1; David S. Clark, Legal Education, in Comparative LaW And Society (David S. Clark ed., 2012).

${ }^{6}$ See Christoph Schönberger, Der “German Approach": Die Deutsche StaAtsrechtslehre im Wissenschaftsvergleich (2015).

${ }^{7}$ On the sociology of science more broadly, see Mario Kaiser \& Sabine Maasen, Wissenschaftssoziologie, in HANDBUCH SPEZIELle SOZIOLOGIEN, supra note 1.
} 


\section{B. Why Compare Socio-Legal Studies? Aims of Comparison and Potential Research Questions}

Assessing how socio-legal studies are pursued and taught differently in different countries helps us not only to understand and explain commonalities, differences, and context dependencies but also to translate between different academic languages, and to reflect upon our own research methods and techniques or the legal education in our home country. Such scholarly endeavors may take a more sociological approach: Seeing socio-legal studies as a social institution and socio-legal scholars as a sociological group. Or it may take a more historical approach: Assessing how the field of socio-legal studies emerged in a particular context and as a reaction to particular events.

The findings of such a scholarly endeavor prove helpful for scholars planning research in other parts of the world and for cross-country collaborative research projects. They also allow scholars and institutions in different parts of the world to learn from each other, see potential gaps with regard to their own research and teaching, and close these gaps. Some personal experience might serve as an example here: Talking with socio-legal scholars from the US and the UK several years ago, I first heard about the process of "getting through ethics" before carrying out fieldwork, interviews, or ethnographic research. In the German law faculty, where I was based, legal scholars did not have to approach an ethics committee to have their research project scrutinized before pursuing such endeavors. The underlying assumption for why no such ethical scrutiny was needed might have been that research in law means doctrinal research—or, potentially, research on legal history - where ethical issues play no central role. But at German law faculties, too, some researchers engage in empirical research projects that might involve ethical questions. German law faculties could thus learn from the institutional and procedural frameworks of foreign law faculties and the experiences of scholars in other parts of the world, reflect upon their own practices, and implement new standards and requirements. Comparative scholarship about socio-legal studies goes beyond mere subjective impressions that researchers may collect during a research stay abroad or through an informal conversation with foreign scholars at international conferences. It provides us with systematic and objective findings, which are much more robust and reliable than individual experiences, and thus serves the process of self-reflection and improvement much better than vague personal impressions.

The findings of such a comparative endeavor on socio-legal studies may also be useful for political decisionmakers who decide upon reforms regarding research funding and legal education - most importantly, about the question of what kind of lawyers, judges, lawmakers, and legal academics the country aspires to "produce" and whether a socio-legal approach in legal education and scholarship may serve this purpose of educating good lawyers better than a purely doctrinal approach. Foreign examples of socio-legal elements in research and teaching, again, may lead the way for such reform. When we seek to assess how socio-legal scholarship and teaching differs in different parts of the world, we can address a large variety of potential aspects. These aspects range from the development of the field of socio-legal studies to the scholarly outcomes produced by research, the methods used in pursuing this scholarship, the people who work in this field, the institutions they work at, and the subjects that feature in teaching. Depending on our research aim, our motivation, and our fields of interest, the research questions we pose will differ. A few potential research topics and questions will be suggested here.

We may, for instance, look at the historical development of the field of socio-legal studies and ask: When, how, and why did socio-legal scholarship emerge in a particular country? What was, and is, the relationship between socio-legal studies and doctrinal legal scholarship? Which aims inform socio-legal scholarship? What do socio-legal scholars perceive as important about their work and where do they see their unique contribution? What role does the socio-legal approach play in legal education?

We could also engage with the impact that socio-legal studies have had on the law and the legal culture in a particular country by asking: Has the socio-legal education of young lawyers 
influenced how they think about and interpret the law when they later find themselves in the positions of practicing lawyers, judges, lawmakers, or academics? And if so, has this different way of thinking about the law shaped the legal landscape of the particular country-that is, does the law look different in countries with strong elements of socio-legal education as compared to those where law students are only trained in doctrinal law?

Other than that, we could compare the research topics that socio-legal scholarship addresses and the research methods that scholars use across the globe by assessing: Which topics, which areas of law, and which regions of the world feature most prominently in socio-legal research and teaching? Which (inter)disciplinary methods do researchers use to deal with these topics and why?

We may also think about the institutional context of socio-legal studies and inquire: Where are socio-legal studies pursued-at universities or other research institutions, in law faculties, or in sociology departments? How does the institutional context, including the possibilities of state- or third-party funding, affect socio-legal research and teaching?

Another aspect of comparison would be to look at researchers' biographies, their self-perception, and their perception of the field of socio-legal studies, by asking: What are the academic backgrounds of socio-legal scholars? Which personal experiences led them to pursue a particular socio-legal project? How do researchers perceive the role of the field of socio-legal studies and how do they see their own role as socio-legal scholars within that field?

Once we are clear about our research aim and have chosen a corresponding research question, the next step is to decide about the objects of our comparative endeavor: First and foremost, the countries that we seek to compare.

\section{What to Compare? Questions of Case Selection and the Examples of Germany and the UK}

When comparing socio-legal studies, general questions that we ask-for instance, in comparative law, or comparative endeavors more generally-become important. One such question is about how we select the entities that we seek to engage with for the comparison to be meaningful-in the case of a cross-country comparison, the countries whose socio-legal studies landscape we seek to study and juxtapose. Mill distinguished between comparisons that look at very different cases in order to explain a common variable - "method of agreement" —or very similar cases that differ in a particular aspect in order to explain a variable that the two units do not share- "method of difference." In the words of Creutzfeldt, Kubal, and Pirie, "the comparison may start from an assumption of similarity - in form, purposes or context-in order to identify significant differences or it may identify significant similarity across social and cultural divides." "Hirschl distinguishes even further and mentions five different ways of case selection: To choose 1) "most similar cases"; 2) "most different cases"; 3) "prototypical cases"; 4) "most difficult cases"; or 5) "outlier cases."10

Another question is how many entities we choose to compare. As with the question of case selection, this choice certainly depends on the aim that we seek to pursue by making the comparison. Single case studies or small-N studies - those that involve only one or a few countries-allow for detailed analysis and provide in-depth insights, while large- $\mathrm{N}$ studies-comparisons involving many countries - allow for more generalizability. ${ }^{11}$

\footnotetext{
${ }^{8}$ John Stuart Mill, Of the Four Methods of Experimental Inquiry, Comparative Methods in the Social SCIENCES (Alan Sica ed., 2006) (1843).

${ }^{9}$ Naomi Creutzfeldt, Agnieszka Kubal \& Fernanda Pirie, Introduction: Exploring the Comparative in Socio-Legal Studies, 12 INT'L J.L. CONTEXT 377, 386 (2016).

${ }^{10}$ Ran Hirschl, The Question of Case Selection in Comparative Constitutional Law, 53 AM. J. CoMP. L. 125 (2005).

${ }^{11}$ See also Creutzfeldt et al., supra note 9.
} 
If we look at Germany and the UK, we notice both similarities and differences with regard to the emergence and development of the field of socio-legal studies. In both countries, socio-legal approaches developed in opposition to mainstream "black letter law" or traditional doctrinal legal studies. Socio-legal approaches were "proclaimed as radically different from the work previously done in law departments in general, and by jurisprudential scholars in particular," 12 and as "antimainstream within jurisprudence."13

In Germany, the sociology of law emerged comparatively early, in the wake of the 20th century. Importantly, unlike other special areas of sociology, the sociology of law was not founded and pursued primarily by sociologists, but by lawyers. ${ }^{14}$ In the 1960s and 1970s, German law schools witnessed a second wave in which the sociology of law enjoyed particular prominence in research and teaching. In a third wave that has continued since the new millennium, the field has further diversified and been featured under different labels, including the sociology of law, law and society, or law in context studies and interdisciplinary legal research-here, collectively referred to as socio-legal studies. Despite its 100-year-long tradition, however, to date, socio-legal scholarship remains marginalized in Germany. In 2007, one commentator wrote:

In Germany, there exists no scientific sociology of law community with an established association or elaborate academic visibility comparable to the Law and Society Association in the United States. Rather, there is a weakly tied circle of lawyers, sensitized in sociological thinking and informed about certain issues, and another group, consisting of sociologists interested in law. Both groups shift in the no-man's land between sociological jurisprudence and legal sociology. They are homeless minds in the landscape of German universities, outlaws in legal faculties and outsiders in the social sciences. Qualification in both subjects is unusual, and most have other responsibilities in teaching and research as well. ${ }^{15}$

While this situation has changed somewhat in the thirteen years since that comment was published, with the establishment of new institutes and research groups-which I will address below-overall, socio-legal studies remain a niche area in German legal scholarship and legal education. Demands by the German Council of Science and Humanities for a stronger socio-legal approach-through "strengthening the foundational subjects [which include sociology of law], intensifying exchanges within and outside the discipline and opening up legal scholarship towards other academic disciplines"16 _ have so far not led to visible changes in German legal education.

This differs significantly from the UK. Here, the emergence of socio-legal studies occurred somewhat later than in Germany and has its origins in the 1960s. But the development of the field was steadier and reached a broader audience. Scholars have even held that "socio-legal study is now the dominant approach taken by most academics in British university law schools," at least when using a broad definition and understanding socio-legal studies as "the use of concepts or methods taken from the social sciences and humanities in the study of legal phenomena," and including the work of those using critical legal theory approaches. ${ }^{17}$

\footnotetext{
${ }^{12}$ Campbell \& Wiles, supra note 2, at 549. For a juxtaposition on doctrinal legal scholarship and socio-legal studies in Germany, see Julika Rosenstock, Tobias Singelnstein \& Christian Boulanger, Versuch über das Sein und Sollen der Rechtsforschung: Bestandsaufnahme eines interdisziplinären Forschungsfeldes, in INTERDISZIPLINÄRE RECHTSFORSCHUNG:

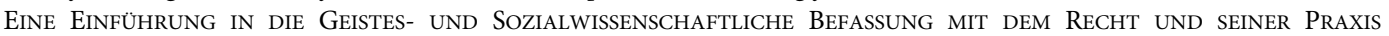
(Christian Boulanger, Julika Rosenstock \& Tobias Singelnstein eds., 2019).

${ }^{13}$ Machura, German Sociology of Law, supra note 1, at 506.

${ }^{14} I d$.

${ }^{15}$ Lucke, supra note 1.

${ }^{16}$ Wissenschaftsrat, Prospects of Legal Scholarship in Germany: CurRent Situation, Analyses, ReCOMmENDATIONS 13 (2012), https://www.wissenschaftsrat.de/download/archiv/2558-12_engl.pdf.

${ }^{17}$ Clark, United Kingdom, supra note 2.
} 
I will revisit the examples of socio-legal studies in Germany and the UK-in the following sections on sources, methods, and challenges in comparative endeavors - to illustrate my broader arguments and suggestions.

\section{What to Compare? Sources and Methods of Data Collection}

What do we look at when we seek to compare socio-legal studies? Again, potential objects of research are manifold. They include-among others-research institutions, publications, socio-legal scholars, and teaching, as I will elaborate in the following sections. The choice of research objects is closely linked to the choice of methods for data gathering. In particular, when we research in and about a country that is not our home country, the feasibility of the data collection needs to be considered carefully. "If we want to go beyond 'comparison by juxtaposition' we will need to establish some sort of working relationship with those who know more about other systems than we do," states Nelken. ${ }^{18}$ He distinguishes three different approaches in conducting research in a foreign environment: 1) "[B]eing virtually there"-the researcher relies on reports and scholarship by local experts; 2) "researching there"-short research visits to the respective country, for instance, to conduct interviews; and 3) "living there"-conducting ethnographic research over a long period of time, for instance, as an "observing participant." 19 Our choice of a research object determines our choice of how to conduct the research and collect the data, and vice versa. For instance, if we seek to study journal articles to learn more about socio-legal studies in a particular country, "being virtually there" might suffice for our research project. If, however, we attempt an ethnographic study of a particular socio-legal research institution, "living there" or "researching there" is a precondition.

\section{Institutions}

Studying institutions of socio-legal scholarship provides us with insights about the locales in which socio-legal studies emerged and through which socio-legal scholars-or the socio-legal "movement," as it has been termed-stay connected. I understand institutions here in a broad sense, including not only university departments, research clusters, centers, and independent research institutes but also socio-legal associations, conferences, publishing houses, journals, and blogs. I thus refer to journals and blogs not as conglomerates of the articles therein-in other words, the publications that I address below_-but as institutional entities, which through their editorial boards or their members and their agreed upon thematic focuses position themselves as actors in the field of socio-legal studies.

In the UK, the law schools at the Universities of Warwick and Kent, which were founded by the government in the late 1960s, were dedicated to the study of "law in context." 20 Later, several other law schools, including those at Birkbeck College, London, Cardiff, and Keele, as well as the London School of Economics, joined Warwick and Kent in their socio-legal approaches. ${ }^{21}$ In 1972, the University of Oxford created the Centre for Socio-Legal Studies. In the same year, a number of academic lawyers and social scientists organized the Socio-Legal Group to hold regular conferences. ${ }^{22}$ In 1990, the group developed into the Socio-Legal Studies Association (SLSA), which runs one of the key annual conferences on socio-legal studies. Central journals for socio-legal research include the Journal of Law and Society, Feminist Legal Studies, the International Journal for the Sociology of Law, Social and Legal Studies, Law and Policy, and

\footnotetext{
${ }^{18}$ David Nelken, Doing Research into Comparative Criminal Justice, in THEORY AND Method IN SOCIO-LEGAL RESEARCH 284 (Reza Banakar \& Max Travers eds., 2005).

${ }^{19} \mathrm{Id}$.

${ }^{20}$ Clark, United Kingdom, supra note 2.

${ }^{21} I d$.

${ }^{22}$ Feenan, supra note 2.
} 
Law and Critique. ${ }^{23}$ Furthermore, longstanding law journals, such as Legal Studies, also largely publish socio-legal research. ${ }^{24}$

In Germany, the second wave of socio-legal studies in the 1960s and 1970s led to the establishment of university institutes and chairs to focus on the sociology of law, both in the faculties of law and, less often, in the social science faculties. Two of these newly established institutes included the Institut für Rechtssoziologie und Rechtstatsachenforschung at Free University Berlin and the Arbeitskreis für Rechtssoziologie at the University of Cologne. ${ }^{25}$ The Universities of Stuttgart, Freiburg, Konstanz, and Munich—and later Halle-followed. ${ }^{26}$ Since 1972, sociologists of law have organized in the Sektion Rechtssoziologie of the German Sociological Association and, since 1976, in the Vereinigung für Rechtssoziologie-later renamed Vereinigung für Recht \& Gesellschaft. A third wave of socio-legal activity has occurred since the new millennium, with the establishment of the Law and Society Institute-today the Integrative Research Institute Law \& Society-in 2008, the research Network Law in Context (Recht im Kontext) in 2010-both at Humboldt University-and the Käte Hamburger Kolleg Law as Culture (Recht als Kultur) in 2010, at the University of Bonn. In 2019, the Institut für Sozialforschung in Hamburg and the Chair for Rechtssoziologie of the University of Bern formed a new Research Cluster on Legal Sociology. Socio-legal studies also take place at different Max Planck Institutes-such as the one for the Study of Societies in Cologne and the one for Social Anthropology in Halle-which bring together international researchers from around the world who contribute to discussions with new perspectives. In Germany, the main medium for socio-legal studies is Zeitschrift für Rechtssoziologie. Other journals that publish theoretical or empirical research on law and society include Kritische Justiz, Rechtstheorie, Demokratie und Recht. More recently, blogs, such as Rechtswirklichkeit, ${ }^{27}$ have also become important sites for the dissemination of socio-legal scholarship.

For the purpose of comparing these and other institutions, data can be gathered in different ways. First of all, we can use texts about sites of socio-legal studies as data. This could be selfdescriptions of certain institutions, such as university departments, associations and conferences, conference reports, or scholars' descriptions about specific institutions. Articles in journals or the self-descriptions of particular journals on their websites and through editorials also serve as data. Seron, Coutin, and White Meeusen, for instance, studied addresses delivered by presidents of the US Law and Society Association (LSA) and LSA meeting calls. They argue that these "demonstrate how the boundaries of the field are established and contested." ${ }^{8}$

To collect data on institutions, we may also draw on ethnography and conduct fieldwork in a particular locale of socio-legal research, such as a research center, an association, or a conference. The methods used in organizational ethnography ${ }^{29}$ might be helpful here. For instance, observational research, a well-established strategy to study the performance of organizational settings, ${ }^{30}$ can be used to gather data about sites of socio-legal studies. It requires that the process of observation is recorded through field notes, which then serve as a-necessarily selective-representation of what occurred. ${ }^{31}$

\footnotetext{
${ }^{23}$ See Clark, United Kingdom, supra note 2.

${ }^{24} \mathrm{Id}$.

${ }^{25}$ See Lucke, supra note 1 .

${ }^{26} I d$.

${ }^{27}$ ReCHTSWIRKLICHKEIT, https://barblog.hypotheses.org/ (last visited Aug. 5, 2020).

${ }^{28}$ Carroll Seron, Susan Bibler Coutin \& Pauline White Meeusen, Is There a Canon of Law and Society?, 9 ANN. REV. L. \& Soc. SCI. 287, 287 (2013).

${ }^{29}$ On the ethnography of organizations, see HELEN B. SCHWARTZMAN, ETHNOGRAPHY IN OrganizATIONS (1995); see also Organizational Ethnography: Studying the Complexities of Everyday Life (Sierk Ybema et al. eds., 2009).

${ }^{30}$ Sharyn Roach Anleu \& Kathy Mack, Law and Sociology, in Routledge HANDBook of Socio-Legal TheORY AND Methods, supra note 4, at 150.

${ }^{31} I d$. at 151 .
} 


\section{Publications}

A second object of research could be publications. Here, I speak about the texts that have been published, rather than the journals or publishing houses that I mentioned above in the section on institutions. A first set of publications worth analyzing are monographs and articles that engage with specific socio-legal phenomena and are located at the interface of law and other disciplines, including anthropology, cultural studies, economics, geography, history, international relations, philosophy, politics, psychology, and sociology. A second set of texts worth studying includes reflections upon the emergence and development of the field of socio-legal studies, and its methods, aims, and shortcomings. Textbooks often provide both an overview of the field as well as detailed engagements with specific socio-legal questions. ${ }^{32}$ Comparing textbooks cross-nationally "can give a sense of the way the field is conceptualized and taught in different states" and allows the reader to "see the field through different eyes." 33

Publications can tell us, among other aspects, something about the history of socio-legal studies and its protagonists, the topics that socio-legal scholarship addresses, the countries it is mostly concerned with, and the methods that socio-legal researchers use. At the same time, by merely looking at the written text, a number of questions usually remain unanswered. For instance, these could regard scholars' motivation for delving into the particular research project and their broader aims in pursuing socio-legal studies. Therefore, we have to engage with scholars themselves to get a more coherent picture of socio-legal scholarship.

\section{Scholars}

Scholars and their biographies are a third potential object of research when comparing socio-legal studies in different parts of the world. Textbooks and articles about socio-legal studies frequently relate the history of the field by referring to a number of influential-mostly male-scholars and their key texts. ${ }^{34}$ Commentators thereby frequently invoke those scholars' biographies as well as the socio-political context in which they lived as being particularly influential in shaping scholars' research, and thereby the development of the field of socio-legal studies or a particular subfield. When speaking about Eugen Ehrlich, for instance, commentators rarely fail to address the fact that Ehrlich lived in the Bukowina - a rural region where official state law played a subordinate role and people instead tended to organize their lives according to various customary norms - to explain why Ehrlich came up with his concept of living law. ${ }^{35}$ Commentators have also shown that national socialism in Germany destroyed the early attempts of socio-legal studies and pushed out Jewish socio-legal scholars. ${ }^{36}$ With respect to the UK, researchers have demonstrated how British scholars - who had gained experiences with law and society studies in the US - brought their knowledge back to the UK, thereby transforming both British scholarship and teaching. ${ }^{37}$

It is not only the personal history, but also the academic background of socio-legal studies, that is informative when assessing socio-legal studies. As Machura points out, unlike in the UK, in German law schools, permanent employment usually requires legal qualifications and thus excludes social

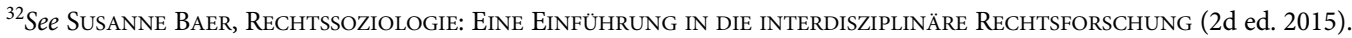

${ }^{33}$ Anthea Roberts, Is International LaW InTERnAtional? 32, 34 (2017).

${ }^{34}$ On the role of the "canon" in socio-legal studies, see Carroll Seron \& Susan S. Silbey, Profession, Science, and Culture: An Emergent Canon of Law and Society Research, in THE BlACKWEll COMPANION TO LAW AND SOCIETy (Austin Sarat ed., 2004); see also Seron et al., supra note 28.

${ }^{35}$ Machura, German Sociology of Law, supra note 1, at 41; BAER, supra note 32, at 30; Brian Z. Tamanaha, A Vision of SocialLegal Change: Rescuing Ehrlich from "Living Law," 36 L. \& Soc. INQUiRY 297, 311 (2011); Walter Fuchs, Erkundung der Theorielandschaft: Klassische rechtssoziologische Ansätze, in INTERDISZIPLINÄRE RECHTSFORSCHUNG: EINE EINFÜHRUNG IN Die Geistes- Und Sozialwissenschaftliche Befassung mit Dem Recht Und SEINer PraXis, supra note 12, at 34-35.

${ }^{36}$ See Thomas Raiser, Krise der Rechtssoziologie in Deutschland, NeUE JuRISTISCHE WochensCHRIFT (July 26, 2007).

${ }^{37}$ See Creutzfeldt, supra note 4 , at $15-16$.
} 
scientists. ${ }^{38}$ This means that socio-legal scholarship taking place at German law schools is conducted by scholars formally trained in law and not usually in sociology or any other discipline.

Studying scholars and their experiences and views allows us to assess "a mass of lived experience and wisdom" ${ }^{39}$ about socio-legal studies, which we can access using different methods of data collection. Autobiographical, oral, or written accounts by scholars who reflect upon their own role in shaping the field of socio-legal studies provide for interesting data. The Centre for Law and Society at the University of Cardiff, for instance, makes available online the videos of a "socio-legal conversation" series in which scholars narrate their personal stories. ${ }^{40} \mathrm{We}$ may also conduct (expert) interviews or surveys with scholars ourselves. Cownie, for instance, examined "the everyday lives of legal academics, their attitudes towards, and beliefs about, teaching, research and administration, their contacts with colleagues in other institutions" by conducting semi-structured interviews with academics teaching and researching law in English universities. ${ }^{41}$ Creutzfeldt interviewed British and US-American socio-legal scholars to assess "how the interviewees experienced and saw themselves during the socio-legal movement" and to "give voice to some of the personal developments that coincided with and contributed to the institutional development of law and society." ${ }^{2}$ She notes that "being a socio-legal scholar today means something very different to being a socio-legal scholar 50 years ago." ${ }^{3}$ In her interviews with the early generation of socio-legal scholars, she noticed in particular their "emotions and enthusiasm about wanting to make a difference and needing to change the status quo"-something that she misses among today's scholars, whose agendas are too often guided by "a notion of angst" about promotion, tenure, or research funding, "rather than wanting to change the world."

While research is the one central pillar of the professional life of academic scholars, teaching is the other, and I suggest making it a fourth object of research in the attempt to compare socio-legal studies.

\section{Teaching}

Looking at how law in general and socio-legal studies in particular are taught at different institutions around the world could help answer the question of whether the aim of the early sociolegal studies, which was "to broaden the study of law from within" or to teach "contextual law," 45 has been fulfilled. In the UK, scholars have held that socio-legal studies are today "an important dimension of mainstream legal education," 46 thereby referring to findings that about half of the British legal academics claim to adopt a socio-legal approach in their teaching, and many others believe it is important to refer to "contextual issues" in their teaching. ${ }^{47}$ For Germany, scholars have pointed out that socio-legal studies play a less important role in legal education than the core doctrinal subjects: The sociology of law usually features in the German legal curriculum only as an elective Grundlagenfach (foundational subject), and scholars perceive it as an "auxiliary science" to the law. ${ }^{48}$ Scholarship has also shown that while most universities offer courses on law and society,

\footnotetext{
${ }^{38}$ See Machura, Milestones and Directions, supra note 4.

${ }^{39}$ Creutzfeldt, supra note 4 , at 9.

${ }^{40}$ Centre of Law and Society, CARDIFF U., https://www.cardiff.ac.uk/research/explore/research-units/centre-of-law-andsociety (last visited Aug. 5, 2020). For a similar format offered by the Center for the Study of Law and Society at Berkeley Law, see Conversations in Law and Society, U.C. BERKELEY SCH. L., https://www.law.berkeley.edu/research/ center-for-the-study-of-law-society/conversations-in-law-and-society/ (last visited Aug. 5, 2020).

${ }^{41}$ Fiona Cownie, Legal Academics Cultures ANd Identities 2 (2004).

${ }^{42}$ Creutzfeldt, supra note 4 , at 10 .

${ }^{43} \mathrm{Id}$. at 32.

${ }^{44}$ Creutzfeldt, supra note 4 , at 32 .

${ }^{45}$ Campbell \& Wiles, supra note 2 , at 550.

${ }^{46}$ Sommerlad, supra note 2 , at 60 .

${ }^{47}$ CownIE, supra note 41.

${ }^{48}$ Machura, German Sociology of Law, supra note 1, at 42.
} 
the teaching of socio-legal topics in law faculties and sociology departments runs somewhat parallel, without any connections. ${ }^{49}$

Curricula, course descriptions, syllabi, and teaching modules are important data here. Seron, Coutin, and White Meeusen, for instance, compared eighteen syllabi of law and society coursesas taught around the United States - in order to compile a list of commonly assigned books and articles. ${ }^{50}$ They categorize the key texts that form part of this list into five broad themes: 1) "Situating Law and Society," 2) "Disputing-Individual and Collective," 3) "Law and Social Change," 4) "Law in Everyday Life," and 5) "Law as Institution." In a similar fashion, Dollmaier and De Souza analyzed course descriptions of university courses across the globe on "Law and Development" and found "highly diverse approaches to both 'law' as well as 'development."'51 Apart from gathering such textual material, we can also generate data through the observation of classes or surveys, and interviews with teachers and students.

As this short overview has shown, we have a number of methods of data collection at hand when studying research institutions, publications, scholars, and teaching to understand socio-legal studies. The data collected can be large aggregate data—such as textbooks or articles-or smaller sets of properly, randomly selected, samples of data-such as course descriptions or surveys-as well as observations, conversations, and (expert) interviews. Having chosen our research object and a method of data collection, a next question in our endeavor to assess socio-legal studies in different parts of the world would be to choose a method to analyze the data collected and actually compare the findings from our research in different contexts.

\section{E. How to Compare? Methods of Data Analysis}

To assess the data we have collected-such as textbooks, articles, course descriptions, or transcribed interviews - and actually pursue a comparison, again, we have a number of very different methods at our disposal. We can distinguish between qualitative and quantitative methods of data analysis. Quantitative methods serve to test or confirm theories and assumptions, and enable researchers to establish generalizable facts about a topic. Qualitative methods help to understand concepts, thoughts, or experiences, and to gather in-depth insights. Here again, the specific research question we have in mind paves the way to the method we should choose. Therefore, there is no "correct" method as such. In this section, I mention a few selected methods to suggest options for the analysis and comparison of data on socio-legal studies, leaving aside a vast number of other methods that might serve this purpose too. The methods I discuss are content analysis, critical discourse analysis, thick description, causal process tracing, and framing analysis.

The attempted research project could seek to assess which topics, areas of law, and regions of the world feature most prominently in socio-legal research and teaching, and which (inter)disciplinary methods researchers use most often. Such questions can be tackled with content analysis. Content analysis observes patterns of content in a given text to draw text-external inferences. It does so by annotating the text with different codes to assess the absolute or relative frequencies of words, or larger syntactic or semantic units in a given text corpus. ${ }^{52}$ For example, to explore how international law is understood and taught differently in different parts of the world, and how "nationalized" or "denationalized" the field is in different contexts, scholarship has assessed the content of international law textbooks from different states-in particular, whether the books primarily cited domestic, international, or foreign case law. ${ }^{53}$

\footnotetext{
${ }^{49}$ See Barbara Heitzmann, Lehre der Rechtssoziologie an deutschen Hochschulen, 25 ZEITSCHRIFT FÜR RECHTSSOZIOLOGIE 249 (2003).

${ }^{50}$ Seron et al., supra note 28 , at 287.

${ }^{51}$ Thomas Dollmaier \& Siddharth De Souza, Beyond “Moments” and into Different “Time Zones”?: Exploring The Teaching of LaW and Development (forthcoming).

${ }^{52}$ See Stefan Titscher, Michael Meyer, Ruth Wodak \& Eva Vetter, Methods of Text and Discourse Analysis: In SEARCH OF MEANing (2000).

${ }^{53}$ See Roberts, supra note 33.
} 
Other scholars looked at the shifts in the subject area of books and journal articles on political economy to learn more about the identity and the development of the field, ${ }^{54}$ and to find out about the methods that are primarily used in the respective research projects and the gender and country of origin of the authors. ${ }^{55}$ Content analysis of specific journals, textbooks, book series, conference proceedings, blogs, and newsletters from the field of law and society could identify which thematic focuses featured prominently in different countries, how these focuses shifted over time, or which methods socio-legal scholars have predominantly used. With respect to the UK, Clark holds that some areas-among them, civil and criminal justice, family law, and gender relations-have received great attention among the socio-legal community, while others areas - such as land law and equity-have been largely neglected. ${ }^{56} \mathrm{He}$ also states that in socio-legal research in the UK, large-scale empirical research is "relatively underdeveloped," and that "most socio-legal work has focused on theoretical analysis, policy work, qualitative analysis, or small-scale empirical enquiry." 57 Content analysis could support these claims with statistical data and compare the findings from the UK with those from other parts of the world.

If we seek to go beyond very specific questions on the content of specific text corpuses-and are instead interested in broader discourses in the field of socio-legal studies over a long period of time and across countries - we could assess and compare these, with the help of discourse analysis, and relate them to their respective social, cultural, and political context. Discourse analysis is the analysis of relationships between a text or other forms of concrete language use and its social conditions, ideologies, and power relations. ${ }^{58}$ Discourse analysis is interpretative, explanatory, and based on the premise that discourses "are not only embedded in a particular culture, ideology or history, but are also connected intertextually to other discourses." 59

If our research project regards a particular site of socio-legal knowledge production-a research center, a conference, an association-and the people that interact in this site, we may use methods such as thick description, ${ }^{60}$ a method used, among others, in anthropology, sociology, and history. Thick description "refers to an idea of highly detailed, intricate description of particularities, emphasising personal experience of a culture 'from the inside,' or through a kind of empathy allowing sensitive, rich appreciation of the outlook of those living in a particular environment." ${ }^{\prime 1}$ This includes the scientific observation of people's behavior, and not only the description of that behavior, but also their subjective explanations for their behavior and the context in which these people act, to add deeper meaning to the observation.

Another central question we may pose in our research pertains to the impact that the socio-legal studies "movement" had on traditional legal studies and teaching, and whether and how it has shaped the way legal academics, practicing lawyers, and lay people think about the law. Creutzfeldt, Mason, and McConnachie state that "[s]ocio-legal studies has had an enormous influence on legal scholarship" in that it has challenged assumptions about "the nature of law, rules and legal thought; the relationship between law and ethics, morality and religion; law, government, and governance; and law and community," and provided "an understanding of the meaning of legal culture and legal

\footnotetext{
${ }^{54}$ See J.P. Sharman \& Catherine Weaver, RIPE, the American School and Diversity in Global IPE, 20 REV. INT'L POL. ECON. 1082 (2013); Renate Mayntz, Changing Perspectives in Political Economy (July 2019) (unpublished Discussion Paper 19/6, Max-Planck-Institut für Gesellschaftsforschung) (on file with author).

${ }^{55}$ See Lima, Enzo, Melina Morschbacher \& Paulo Peres, Three Decades of the International Political Science Review (IPRS): A Map of Methodological Preferences in IPRS Articles, 39 INT'L POL. SCI. REV. 679 (2018).

${ }^{56}$ Clark, United Kingdom, supra note 2.

${ }^{57} I d$.

${ }^{58}$ See TITSCHER ET AL., supra note 52, at 146.

${ }^{59} \mathrm{Id}$.

${ }^{60}$ See Clifford Geertz, The Interpretation of Cultures: Selected Essays (1973).

${ }^{61}$ Roger Cotterrell, Comparative Sociology of Law, in COMPARATIVE LAW AND SocIETY, supra note 5, at 47.
} 
consciousness." 62 And indeed, in many countries, legal scholarship and teaching today looks different than it did fifty or 100 years ago. The role that the socio-legal studies movement has played in this shift can be assessed through causal process tracing. Causal process tracing is engaged with revealing "the process that leads from a causal factor to an outcome" and "makes it possible to enhance the internal validity of a causal claim that ' $x$ matters." ${ }^{63}$ It is particularly useful when we seek to not only explain a single important social event, but to identify and explain more generally the necessary and sufficient conditions that lead to a specific type of outcome. ${ }^{64} \mathrm{With}$ the help of causal process tracing, we could also assess other causal relations-for instance, how the field of socio-legal studies was shaped by particular personalities and their biographies-by particular research projects and influential publications, or by political decisions regarding university regulation and funding. With respect to the UK, Clark stresses the impact of the "personal inclinations of the relatively small number of scholars" on the development of the field. ${ }^{65} \mathrm{He}$ also refers to the importance of the "availability of external funding, the research needs of various government departments and charitable trusts, and the activities of a variety of pressure groups" in shaping the development of socio-legal studies. ${ }^{66}$ Causal process tracing could disentangle these different impact factors and compare the developments in the UK with those in other countries.

Lastly, if we are interested in analyzing how the socio-legal studies movements in different countries "re-framed" discourses about the law, we might draw on frame analysis. This method includes a variety of approaches to studying social constructions of reality, or how people understand specific situations and activities. Goffman, who is credited with coining the term "frame analysis," understood a frame to be the culturally determined definitions of reality that allow people to make sense of objects and events. ${ }^{67}$ But the term has since been used in various forms and by scholars of different disciplines, including social movement studies and political communication. ${ }^{68}$ Frames call our attention to particular aspects and direct our attention away from others, ${ }^{69}$ and can thus be used by movements or other forms of organized interest to guide audiences in a particular direction and to certain conclusions and actions.

Thus, with regard to methods of data collection, methods of data analysis vary widely, and our choice of one or several of these methods depends most importantly on our research aim and our research question. While each method has its advantages, all of them also bear challenges that need to be kept in mind.

\section{F. What to Keep in Mind? Challenges of Comparative Endeavors on Law and Society Studies and Concluding Thoughts}

As with other socio-legal or comparative legal endeavors, projects seeking to assess socio-legal studies in different parts of the world also confront challenges, five of which I want to briefly discuss here.

\footnotetext{
${ }^{62}$ Naomi Creutzfeldt, Marc Mason \& Kirsten McConnachie, Socio-Legal Theory and Methods: Introduction, in RouTLEDGE HANDBOOK OF SOCIO-LEgal TheORY AND Methods, supra note 4, at 3.

${ }^{63}$ Joachim Blatter \& Markus Haverland, Designing Case Studies: Explanatory Approaches in Small-N RESEARCH 79 (2012).

${ }^{64} \mathrm{Id}$. at 80 .

${ }^{65}$ Clark, United Kingdom, supra note 2.

${ }^{66} \mathrm{Id}$.

${ }^{67}$ See Erving Goffman, Frame Analysis: An Essay on the Organization of Experience (1974).

${ }^{68}$ See Mieke Verloo, Mainstreaming Gender Equality in Europe: A Critical Frame Analysis Approach, 117 GREEK REV. SOC. RES. 11, 20 (2005) (defining policy framing as "an organising principle that transforms fragmentary or incidental information into a structured and meaningful policy problem, in which a solution is implicitly or explicitly enclosed”).

${ }^{69}$ See Martin Rein \& Donald Schön, Frame-Reflective Policy Discourse, in Social ScIEnCES And MOdERn STATES: National Experiences and Theoretical Crossroads (Peter Wagner, Carol Hirschon Weiss, Björn Wittrock \& Hellmut Wollman eds., 1991).
} 
First, socio-legal studies is a vast field of scholarship that includes a huge number of subfields, and sometimes its contours are not quite clear. Feenan has prominently asked what the "socio" in socio-legal studies means and pointed out that "[a] number of studies define it in terms of the study of law in its social context. Some other studies broaden that context to include the 'political and economic' ... or add the 'cultural' .... However, the precise relationship between these fields is rarely elaborated." 70 Due to this broadness of the field and its loose definition, any comparative endeavor will have to deal with a vast amount of material and must necessarily be selective when deciding about the data to deal with. Setting clear boundaries for our specific research project and stipulating clear methods on how to select representative data is thus crucial.

Second, socio-legal studies might use different media and different forms of knowledge distribution in different countries. While the textbook, for example, is a prominent form of publication in socio-legal studies in Germany and the dominant tool in teaching, this is not so much the case in the UK, where academic papers might be more important. We thus need to pay attention in the data selection to ensure that we do not overlook a particularly important medium, but we also must not compare apples with oranges.

Third, different terminology is used in different languages to refer to similar things. This has already begun with terms such as socio-legal studies, law and society studies, sociology of law, and empirical or interdisciplinary legal research, but it might also be relevant with regard to research methods and the like. Being aware of these different terminologies is crucial when, for instance, browsing through databases of journals or coding journal articles.

Fourth, those scholars with a legal education are often not formally trained in using empirical methods and often not familiar with nonlegal literatures and concepts. Attempting to pursue a research project for which doctrinal analysis is not enough and seeking to speak to an audience beyond the field of law, however, demands us to be familiar with those sets of methods, concepts, and literature that are used in the social sciences. This requires self-teaching or pursuing courses to acquire those skills and knowledge, an endeavor that might be time consuming and challenging.

Finally, a number of those challenges that comparative endeavors naturally encounter play a role in the comparison of socio-legal studies too. Among other aspects, this concerns questions regarding language barriers and the possibilities to pursue research abroad.

If, however, we overcome these challenges, the endeavor to compare socio-legal studies in different parts of the world promises fruitful outcomes. As I suggested in this Article, it allows us to assess a number of aspects, ranging from the historical development of socio-legal studies to the role of research institutions and the lives of socio-legal scholars. The research questions, objects of research, and methodological approaches that I suggested in this Article are certainly not comprehensive, and comparative endeavors may well look at other aspects and use other tools. Ideally, such comparative endeavors should not only take into account the usual suspects of countries in Europe and North America, but also look at socio-legal studies in other parts of the world, particularly in the global South. The outcomes of such comparative studies would certainly enrich our understanding of socio-legal scholarship and contribute to a cross-national dialogue.

\footnotetext{
${ }^{70}$ Feenan, supra note 2 , at 4 .
} 